\title{
Locomotion Induces Stimulus-Specific Response Enhancement in Adult Visual Cortex
}

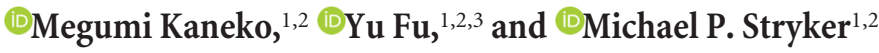 \\ ${ }^{1}$ Center for Integrative Neuroscience and ${ }^{2}$ Department of Physiology, University of California, San Francisco, California 94143 and ${ }^{3}$ Singapore Bioimaging \\ Consortium, Agency for Science Technology and Research, Singapore 138667
}

The responses of neurons in the visual cortex (V1) of adult mammals have long been thought to be stable over long periods. Here, we investigated whether repeated exposure to specific stimuli would enhance V1 visual responses in mice using intrinsic signal imaging through the intact skull and two-photon imaging of calcium signals in single neurons. Mice ran on Styrofoam balls floating on air while viewing one of three different, high-contrast visual stimuli. V1 responses to the stimuli that were viewed by the animal were specifically enhanced, while responses to other stimuli were unaffected. Similar exposure in stationary mice or in mice in which NMDA receptors were partially blocked did not significantly enhance responses. These findings indicate that stimulus-specific plasticity in the adult visual cortex depends on concurrent locomotion, presumably as a result of the high-gain state of the visual cortex induced by locomotion.

Key words: locomotion; mouse; orientation tuning; plasticity; V1; visual cortex

\section{Significance Statement}

We report a rapid and persistent increase in visual cortical responses to visual stimuli presented during locomotion in intact mice. We first used a method that is completely noninvasive to image intrinsic signals through the intact skull. We then measured the same effects on single neurons using two-photon calcium imaging and found that the increase in response to a particular stimulus produced by locomotion depends on how well the neuron is initially driven by the stimulus. To our knowledge, this is the first time such enhancement has been described in single neurons or using noninvasive measurements.

\section{Introduction}

It is well documented that visual experience during a critical period in early postnatal life can profoundly alter the responses of neurons in the developing mammalian visual cortex. In contrast, primary sensory cortex in adult mammals has been thought to be "hard-wired" by comparison. While many recent results have demonstrated some degree of activity-dependent plasticity in adult primary visual cortex (V1; for review, see Karmarkar and Dan, 2006; Espinosa and Stryker, 2012; Gilbert and Li, 2012; Medini, 2014; van Versendaal and Levelt, 2016), most reports of adult plasticity find it to be smaller, slower, and qualitatively different from that in early life. Therefore, steps to expand the

\footnotetext{
Received Dec. 7, 2016; revised Jan. 20, 2017; accepted Feb. 18, 2017.

Author contributions: M.K. and M.P.S. designed research;M.K. performed research;Y.F. contributed unpublished reagents/analytic tools; M.K. and M.P.S. analyzed data; M.K. and M.P.S. wrote the paper.

This work was supported by NIH Grants R01EY02874 and T32MH089920 and by the Simons Collaboration on the Global Brain, Project 325295. M.P.S. is a recipient of the Research to Prevent Blindness Stein Innovator Award. We thank the members of the Stryker laboratory for assistance with and criticism of these experiments.

The authors declare no competing financial interests.

Correspondence should be addressed to Dr. Michael P. Stryker, Center for Integrative Neuroscience and Department of Physiology, University of California, 675 Nelson Rising Lane, San Francisco, CA 94143-0444. E-mail: stryker@phy.ucsf.edu.

DOI:10.1523/JNEUROSCI.3760-16.2017

Copyright $\odot 2017$ the authors $\quad 0270-6474 / 17 / 373532-12 \$ 15.00 / 0$
}

capacity of the adult brain for plasticity are of great interest because of the relevance to recovery from CNS disease and injury and for maintaining cognitive ability well into the last days of life. Previous studies have increased adult plasticity by various invasive and noninvasive manipulations such as environmental enrichment (Greifzu et al., 2014), antidepressant treatment (Maya Vetencourt et al., 2008), inhibitory neuron transplant, (Southwell et al., 2010), and others (for review, see Espinosa and Stryker, 2012). We have shown that exposure to high-contrast visual stimuli during locomotion improved recovery of visual cortical responsiveness from amblyopia (Kaneko and Stryker 2014) and enhanced the plasticity induced in adult cortex by monocular deprivation (Fu et al., 2015). Previous studies using evoked potential recordings through electrodes implanted in the visual cortex reported rapid and persistent increases in responses to repeated stimuli (Frenkel et al., 2006; Cooke and Bear, 2010). We wondered whether the behavioral intervention that we have used in our previous studies, i.e., running plus visual exposure (VE), would enhance responses in the intact visual cortex of normal adults.

Here, we used intrinsic signal imaging through the intact skull, a completely noninvasive technique, to investigate whether repeated exposure to specific stimuli would enhance visual responses in adult mouse primary visual cortex. We found that V1 
responses to the stimuli that were viewed by the animal during daily running on a freely moving spherical treadmill were specifically enhanced, leaving responses to other stimuli unaffected. The enhancement was prevented by an NMDA receptor antagonist and persisted for at least a week following cessation of $10 \mathrm{~d}$ of stimulus exposure. Similar exposure in mice that were not walking or running did not significantly enhance responses. Longitudinal two-photon $\mathrm{Ca}^{2+}$ imaging revealed that the average response magnitude to the exposed orientation was significantly increased, while that to the orthogonal orientation was unchanged. These changes in responsiveness were observed in cells whose initial preferred orientation was close to the experienced orientation and in cells with lower orientation selectivity before exposure, and resulted in an attractive shift of cells' preferred orientation toward the exposed one and a sharpening of orientation tuning.

\section{Materials and Methods}

Animals. C57BL/6J (RRID:IMSR_JAX:000664) wild-type mice were purchased from The Jackson Laboratory and bred as needed, and animals of either sex were used. Animals were maintained in the animal facility at University of California San Francisco and used in accordance with Protocol AN143347 approved by the UCSF Institutional Animal Care and Use Committee. A custom stainless steel plate for head fixation was attached to the skull with dental acrylic under isoflurane anesthesia. The exposed surface of the skull was covered with a thin coat of nitrocellulose (New-Skin, Medtech Products) to prevent desiccation, reactive cell growth, and destruction of the bone structure. Animals were given a subcutaneous injection of carprofen $(5 \mathrm{mg} / \mathrm{kg})$ as a postoperative analgesic. All mice were housed in groups of four or five and kept under standard conditions ( $12 \mathrm{~h}$ light/dark cycle, ad libitum access to food and water) between recordings and daily running on the treadmill.

Intrinsic signal optical imaging. Repeated optical imaging of intrinsic signals was performed as described previously (Kaneko et al., 2008). Five to $7 \mathrm{~d}$ after the head plate implantation, the first imaging of intrinsic signals was performed to measure baseline responses. The mouse was anesthetized with isoflurane (3\% for induction and $0.7 \%$ during recording) supplemented with intramuscular injection of chlorprothixene hydrochloride ( $2 \mu \mathrm{g} / \mathrm{g}$ body weight) and images were recorded transcranially through the window of the implanted head plate. Intrinsic signal images were obtained with a Dalsa 1 M30 CCD camera with a $135 \times 50$ $\mathrm{mm}$ tandem lens (Nikon) and red interference filter $(610 \pm 10 \mathrm{~nm})$. Frames were acquired at a rate of $30 \mathrm{fps}$, temporally binned by four frames, and stored as $512 \times 512$ pixel images after binning the $1024 \times$ 1024 camera pixels by $2 \times 2$ pixels spatially. Responses in each mouse were measured with three kinds of visual stimuli: (1) horizontal bars drifting upward or downward, (2) vertical bars drifting leftward or rightward, and (3) the contrast-modulated noise movie. They were generated in MATLAB using Psychophysics Toolbox extensions (Brainard, 1997; Pelli, 1997) and displayed on a LCD monitor $(30 \times 40 \mathrm{~cm}, 600 \times 800$ pixels, $60-\mathrm{Hz}$ refresh rate) placed $25 \mathrm{~cm}$ from the mouse, spanning $\sim 60^{\circ}$ (height) $\times \sim 77^{\circ}$ (width) of visual space. The drifting bar was the full length of the monitor and $2^{\circ}$ wide, and it moved continuously and periodically (Kalatsky and Stryker 2003). The contrast-modulated Gaussian noise movie consisted of the Fourier inversion of a randomly generated spatiotemporal spectrum with low-pass spatial and temporal cutoffs applied at 0.05 cycles per degree and $4 \mathrm{~Hz}$, respectively (Niell and Stryker, 2008). To provide contrast modulation, the movie was multiplied by a sinusoid with a $10 \mathrm{~s}$ period. Movies were generated at $60 \times 60$ pixels and then smoothly interpolated by the video card to $480 \times 480$ to appear $\sim 60^{\circ}$ (height) $\times \sim 60^{\circ}$ (width) on the monitor and played at 30 frames per second. Each recording took $240 \mathrm{~s}$ and was repeated for at least six measurements per animal. During the daily session of running plus VE, animals were exposed to only one of these three stimuli.

Analysis of intrinsic signal images. The ROI within V1 was selected on the response magnitude map evoked by visual stimulation. First, the map was smoothed to reduce pixel shot noise by low-pass filtering using a uniform kernel of $5 \times 5$ pixels. The background area was selected from the area covering $\sim 150 \times 150$ pixels outside of $\mathrm{V} 1$. The ROI was selected by thresholding at $40 \%$ above the average background amplitude, and the response amplitude was then calculated as the average amplitude of pixels within the ROI.

NMDA receptor blockade. The NMDA receptor antagonist 3-(2carboxypiperazin-4-yl)propyl-1-phosphonic acid (CPP; Tocris Bioscience; $10 \mathrm{mg} / \mathrm{kg}$ ) or vehicle solution was injected intraperitoneally $1 \mathrm{~h}$ before running plus VE sessions every day. This dosage was shown to inhibit visual cortical plasticity but not to affect general behavior in adult mice (Sato and Stryker, 2008).

Two-photon imaging of $\mathrm{Ca}^{2+}$ signals. AAV1-Syn-GCaMP6s (University of Pennsylvania Vector Core) was injected stereotaxically into the V1 around P45. Approximately 2 weeks after virus injection, a custom titanium head plate with a 3-mm-diameter window was fixed to the skull and a round glass coverslip ( $3 \mathrm{~mm}$ diameter) was cemented over a craniotomy made over $\mathrm{V} 1$, under isoflurane anesthesia (3\% induction, $1.5-2 \%$ maintenance) supplemented with subcutaneous analgesics injections. Five to $7 \mathrm{~d}$ after window implantation, baseline $\mathrm{Ca}^{2+}$ responses were recorded under the same anesthesia as for the intrinsic signal imaging. Two to $3 \mathrm{~d}$ after recording baseline responses, each animal underwent daily sessions of running plus VE.

Drifting sinusoidal grating stimuli were generated using the Psychophysics Toolbox extensions in MATLAB (MathWorks) and displayed on a LCD monitor (Dell; $30 \times 40 \mathrm{~cm}, 60 \mathrm{~Hz}$ refresh rate) placed $25 \mathrm{~cm}$ from the mouse. Each trial stimulus consisted of a $3 \mathrm{~s}$ grating $(0.05$ cycles per degree, $1 \mathrm{~Hz}$ temporal frequency) followed by a 3 or $4 \mathrm{~s}$ of blank period of uniform $50 \%$ gray. Eight drifting directions in $45^{\circ}$ steps presented in a random sequence were repeated six times per recording set.

Imaging was performed using a Sutter Movable Objective Microscope and a Chameleon ultrafast laser (running at $940 \mathrm{~nm}$ ), controlled by ScanImage (http://scanimage.vidriotechnologies.com). Images were collected at $5 \mathrm{~Hz}, 512 \times 256$ pixels covering $\sim 250 \times 250 \mu \mathrm{m}$ at a depth of $150-300 \mu \mathrm{m}$ from the dura surface.

$\mathrm{Ca}^{2+}$ signal analysis. ROIs corresponding to visually identifiable cell bodies were selected manually, and the nuclear region, which is devoid of fluorescence, was excluded. Cells with overlapping ROIs were excluded from the analysis. The fluorescence time course of each cell was obtained in ImageJ by averaging all pixels within the ROI. Further analyses were performed by a custom written MATLAB program (Fu et al., 2014). Briefly, $\Delta F / F_{0}$ was calculated as $\left(F-F_{0}\right) / F_{0}$, where $F_{0}$ is the baseline fluorescence signal averaged over a $1 \mathrm{~s}$ period immediately before the start of visual stimulation. Visual responses were measured for each trial as $\Delta F / F_{0}$, averaged over the last $2 \mathrm{~s}$ of the stimulus period. Neurons were considered visually responsive when fluorescence changes were significantly related to stimulus (ANOVA across blank and eight direction stimulus periods, $p<0.01$; Ohki et al., 2005), with an average $\Delta F / F_{0}$ at preferred orientations (O_prfs) $>25 \%$. The $O \_p r f$ was determined by fitting the tuning curve with the sum of two Gaussians. The orientation selectivity index (OSI) was computed for responsive cells as $\left(R_{\text {pref }}-\right.$ $\left.R_{\text {ortho }}\right) /\left(R_{\text {pref }}+R_{\text {ortho }}\right)$, where $R_{\text {pref }}$ and $R_{\text {ortho }}$ are the response amplitudes at the preferred and the orthogonal orientation, respectively (Niell and Stryker, 2008).

Statistical analyses. Data were presented as mean \pm SEM, mean \pm SD, or cumulative frequency distributions unless indicated otherwise. Statistical methods used are stated in the result section and/or figure legends. Statistical analyses were performed using Prism 6 (GraphPad Software) or MATLAB (MathWorks).

\section{Results}

Response enhancement measured by intrinsic signal imaging Each animal was acclimated to the running setting by the experimenter's handling and being placed on the Styrofoam ball floating on air for $\sim 15 \mathrm{~min}$ a day for $4-5 \mathrm{~d}$. Baseline intrinsic signal responses were then measured to three different, high-contrast visual stimuli: drifting horizontal bar, drifting vertical bar, and contrast-modulated noise movie (Fig. 1A). Starting 2-3 d later, animals were allowed to run on Styrofoam balls while viewing one of those three visual stimuli 60 min per day for $10 \mathrm{~d}$, 
as described previously (Kaneko and Stryker, 2014). To track the change in visual cortical responses to these visual patterns, we repeated intrinsic signal recordings on day 5 and day 10 , and then on day 17 , one week after stopping the daily running plus VE sessions (Fig. 1A). The parameters for the drifting bars were chosen to elicit strong responses in V1 based on our previous report (Kalatsky and Stryker, 2003). The visual stimuli also included the contrast-modulated stochastic noise matched to the spatiotemporal frequency response of the mouse V1 neurons because it drives nearly all cells in the primary visual cortex to some extent (Niell and Stryker, 2008).

Figure $1 B$ shows examples of intrinsic signal images recorded over time from a mouse that viewed drifting vertical bars during daily running on the ball, revealing a modest increase in the response to the vertical bars and little change in responses to horizontal bars or the noise movie. As a group, mice that viewed vertical bars during running showed a modest but significant increase in response to the same stimulus (Fig. 1C, red circles; baseline, $2.49 \pm 0.84$; day 5 , $3.40 \pm 1.02$; day $10,3.47 \pm 0.96$; twoway ANOVA, $F_{(6,36)}=6.6, p<0.001$ for the interaction effects of visual stimuli and days; $F_{(3,36)}=2.1, p=0.11$ for the effect of days; $p<0.01$ on days 5 and 10 compared to baseline), but responses to other stimuli were unchanged (Fig. 1D, red circles, response to horizontal bars, baseline, $3.39 \pm 1.08$; day 5, $3.28 \pm 1.32$; day 10, $3.09 \pm 1.13$; Fig. $1 E$, response to the noise movie, baseline, $4.00 \pm 0.63$; day 5, $3.93 \pm 0.73$; day $10,3.81 \pm 0.81$; $p>0.05$ on days 5 and 10 vs baseline). Likewise, mice that viewed horizontal bars during running demonstrated a modest but statistically significant increase in responses when tested with the same visual stimulus but not to stimuli that they had not experienced (Fig. $1 C-E$, blue circles; responses to horizontal bars, baseline, $3.15 \pm 1.12$; day 5 , $4.11 \pm 1.43$; day $10,4.34 \pm 1.68$; vertical bars, baseline, $2.73 \pm$ 0.96; day 5, $2.66 \pm 0.93$; day 10, $2.53 \pm 0.95$; noise movie, baseline, $4.30 \pm 0.91$; day $5,4.27 \pm 0.81$; day $10,4.33 \pm 1.16$; two-way ANOVA, $F_{(6,36)}=6.83, p<0.001$ for the interactions of visual stimuli and days; $F_{(3,36)}=4.84, p=0.006$ for the effects of days). A similar change in responsiveness to the exposed stimulus was observed in mice that viewed contrastmodulated noise movie during running (Figs. $1 C-E$, black circles; responses to noise movie, baseline, $4.22 \pm 0.91$; day 5 , $5.56 \pm 1.12$; day $10,5.75 \pm 1.27$; responses to vertical bars, baseline, $2.52 \pm 0.86$; day 5, $2.55 \pm 0.95$; day 10, $2.64 \pm 0.86$; responses to horizontal bars, baseline, $3.07 \pm 1.02$; day 5, $3.04 \pm 1.00$; day $10,2.83 \pm 0.85$; two-way ANOVA, $F_{(6,36)}=$
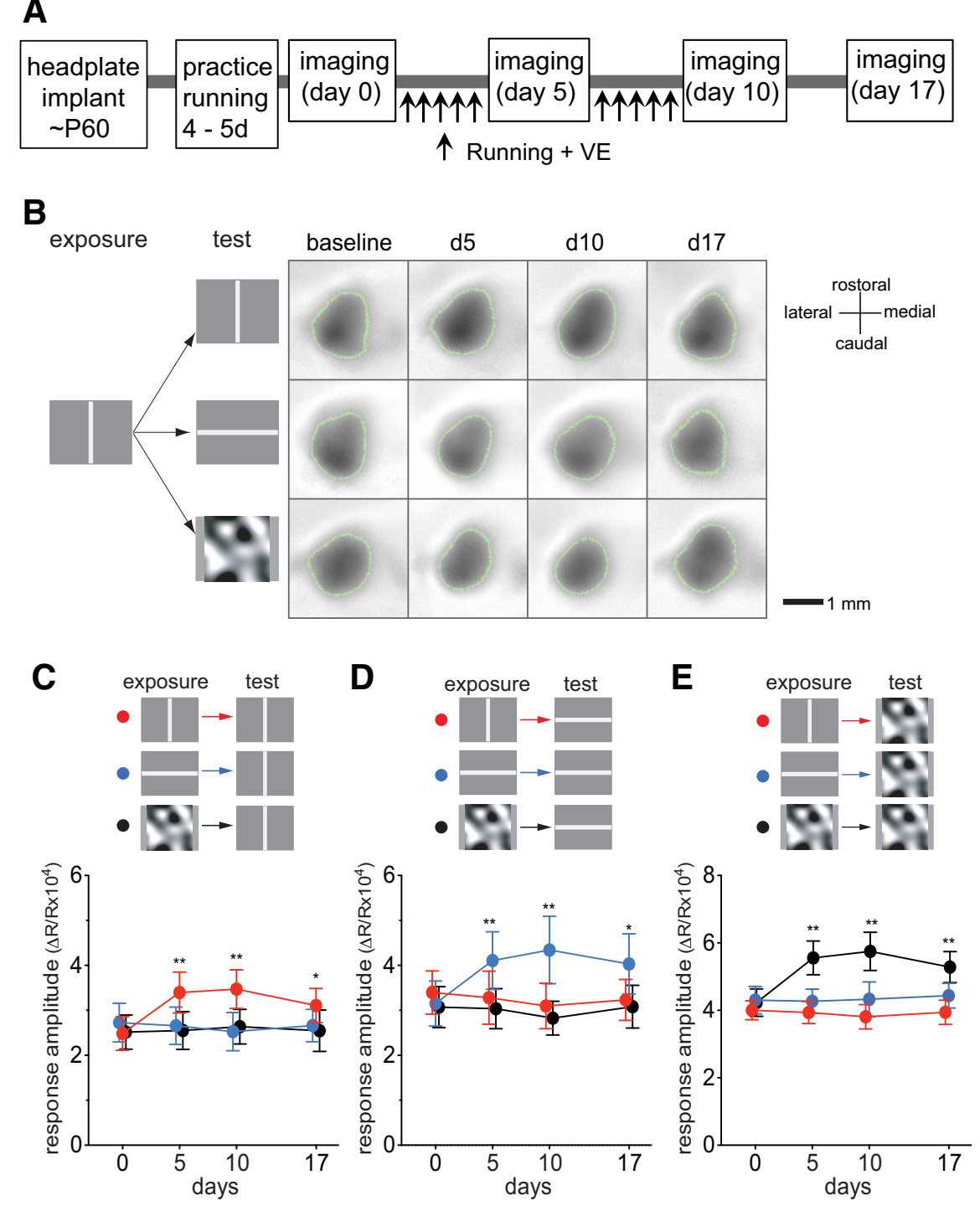

Figure 1. Preferential potentiation of visual cortical responses to the visual stimuli experienced during locomotion. $\boldsymbol{A}$, Experimental schedule. During daily running from day 1 through day 10 , mice were presented with either drifting vertical bars, drifting horizontal bars, or contrast-modulated noise, indicated as "exposure" in $\boldsymbol{B}-\boldsymbol{E}$. In every animal, visual cortical responses to all three calculated. $\boldsymbol{C}-\boldsymbol{E}$, Time course of change in intrinsic signal responses to drifting vertical bars $(\boldsymbol{C})$, drifting horizontal bars $(\boldsymbol{D})$, or contrast-modulated noise $(\boldsymbol{E})$ in animals exposed to the vertical bars (red circles; $n=6$ ), the horizontal bars (blue circles; $n=6$ ) measurements of the averaged response over the ROI were averaged for each animal. ${ }^{*} p<0.05 ;{ }^{* *} p<0.01$ compared with the baseline (day 0) response (two-way ANOVA followed by multiple comparisons with Bonferroni's correction).

$12.28, p<0.001$ for the interaction effects of visual stimuli and days; $F_{(3,36)}=10.29, p<0.001$ for the effects of days). These enhancements had peaked by day 5 with only a slight, insignificant increase on day 10 , and they persisted for at least $7 \mathrm{~d}$ after terminating sessions of running plus VE (Fig. 1C-E, day 17).

One hour per day of running plus VE was sufficient to produce a saturating effect. Increasing the duration of daily running plus VE from 1 to 2 to $4 \mathrm{~h}$ did not produce significantly greater enhancement (Fig. 2).

These observations are similar in magnitude to those of the report by Frenkel et al. (2006), which found an approximate $40 \%$ increase in visually evoked potentials (VEPs) through electrodes chronically implanted into V1 of mice older than 


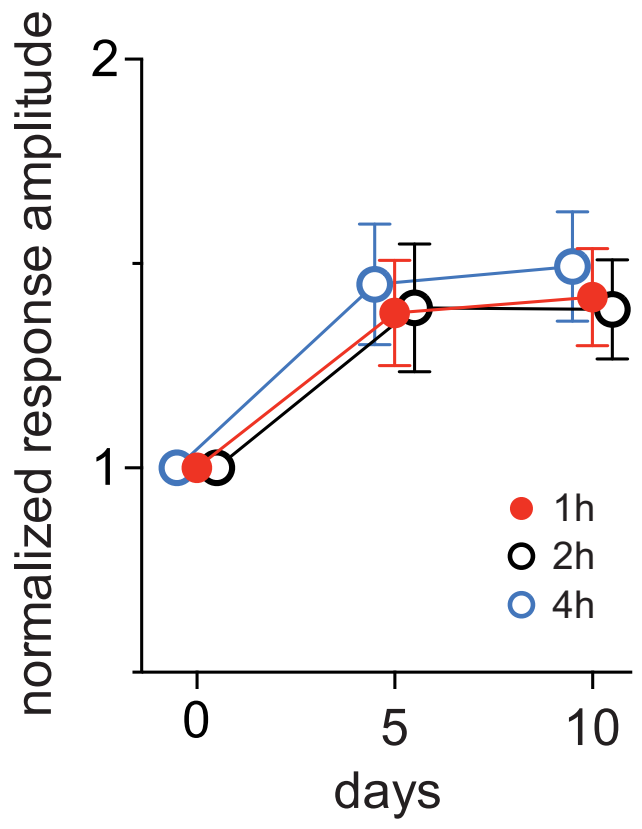

Figure 2. Increasing the duration for running plus visual exposure did not further increase response enhancement. Animals were placed on the spherical floating treadmill daily for $2 \mathrm{~h}$ $(n=4)$ or for $4 \mathrm{~h}(n=4)$ while viewing a vertically oriented bar drifting horizontally. Responses in V1 were measured using intrinsic signal imaging and were normalized to baseline value (day $0)$. Error bars represent the mean $\pm S D$. Data for $1 \mathrm{~h}$ were from Figure $1 C(n=6)$. Changes after $5 \mathrm{~d}$ and $10 \mathrm{~d}$ of running plus visual exposure were not significantly different among three groups (two-way ANOVA).

postnatal day 60 (P60) after short periods of exposure to specific visual stimuli.

\section{Response enhancement depends on NMDA receptor activation}

It has been shown that NMDA receptor activation is required for experience-dependent enhancement in responses in adult visual cortex (Sawtell et al., 2003; Frenkel et al., 2006; Sato and Stryker, 2008). We examined whether the enhancing effects of running plus VE require NMDA-receptor activation. We partially inhibited NMDA receptors by daily systemic administration of the competitive antagonist CPP (Fig. 3A). Running behavior was indistinguishable between vehicle- and CPP-treated animals (percentage of time spent moving, $p=0.877$ for treatments, two-way ANOVA; Fig. 3F; average velocity of movement, $p=0.861$ for treatments, data not shown). Intrinsic signal responses to the visual stimuli that the animals viewed during daily running were enhanced in the vehicle-treated control mice just as in untreated animals (Fig. 3B-D). In contrast, CPP treatment completely blocked these changes over the course of $10 \mathrm{~d}$ (Fig. 3B, baseline, $2.81 \pm 0.96$; day 5, $3.00 \pm 1.03$; day 10, $3.08 \pm 1.05$; Fig. $3 C$, baseline, $3.40 \pm 1.18$; day 5, $3.48 \pm 1.22$; day 10 , $3.60 \pm 1.17$; Fig. $3 D$, baseline, $4.03 \pm 0.83$; day $5,4.45 \pm 1.00$; day $10,4.70 \pm 1.16$; $p>0.05$ on days 5 and 10 vs baseline). This CPP treatment regimen did not change cortical responsiveness in mice that viewed a blank screen of $50 \%$ gray during running (Fig. $3 E$ ).

\section{Locomotion is required for response enhancement}

The findings above reveal that response enhancement depends on visual stimulation, in that looking at a blank screen during running has no apparent effect (Fig. $3 E$ ), and is stimulus specific, affecting only the stimulus viewed during locomotion (Fig. 1). Our previous study had demonstrated that both locomotion and visual stimulation were necessary for the recovery of cortical responses to normal levels in amblyopic adult mice in which one eye had been occluded through the critical period for 5 months (Kaneko and Stryker, 2014). Recovery did not take place with visual stimulation in the home cage, where sustained running was not possible, or with locomotion facing a constant gray screen. But what is the role of locomotion for enhancement in normally reared mice?

To determine whether locomotion is necessary for the enhancement we observed above, as it is for recovery from deprivation, we severely restricted the animal's running by almost completely shutting off the air supply to the system that makes the Styrofoam ball float. To acclimatize animals to restricted locomotion, we started the air flow at $\sim 50 \%$ of normal and gradually decreased it to almost zero over several days. Some mice ( $\sim 40 \%$ of animals that got started practice) failed to be still at all after $10 \mathrm{~d}$ of training and were excluded from the experiments. The movement of the Styrofoam ball was monitored as described previously (Niell and Stryker, 2010). The animals were trained to sit still on the movement restricted ball for $8-10 \mathrm{~d}, \sim 20 \mathrm{~min} / \mathrm{d}$. After recording the baseline intrinsic signal responses on day 0 , animals were placed on the movement-restricted ball while viewing drifting vertical bars $60 \mathrm{~min} / \mathrm{d}$ for $10 \mathrm{~d}$, and intrinsic signal recordings were repeated on days 5 and 10 (Fig. 4A). In contrast to the condition in which the animals were allowed free locomotion, cortical responses to the experienced stimulus were not significantly enhanced when the animals' movement was restricted (Fig. 4B; responses to vertical bars, baseline, $2.03 \pm 0.58$; day 5, $2.03 \pm 0.43$; day $10,2.05 \pm 0.48 ; p>0.05$, repeated measure ANOVA; compare solid pink circles showing enhancement with locomotion).

Although the movement of the ball was restricted in these experiments, it was not completely immobilized, and we noticed that some mice moved it more than others. The four animals that succeeded in moving the ball for a total of nearly an hour over the $10 \mathrm{~h}$ of exposure all showed some degree of enhancement (Fig. $4 C$ ). Indeed, the changes in response magnitude to the experienced stimulus were positively correlated with the duration of movement (Fig. 4C; slope, $0.0029 \pm 0.0011 ; p=0.047$ for deviation from zero; $R^{2}=0.58$; least squares linear regression). Locomotion speed in the movement-restricted condition, while classified as "moving," was much lower $(1-3 \mathrm{~cm} / \mathrm{s})$ compared to that in freely moving condition.

It has been shown that a beneficial effect of acute aerobic exercise in young human volunteers (improvement on an orientation discrimination task after $30 \mathrm{~min}$ on a stationary bicycle) can last at least $30 \mathrm{~min}$ after stopping the exercise (Perini et al., 2016). To test whether locomotor activity confers such benefit in mice, we allowed animals to run for $1 \mathrm{~h}$ while viewing a gray screen and then returned them to the home cage and exposed them to a high-contrast visual stimulus immediately thereafter. A second group had only the exposure in the home cage without the prior running. Intrinsic signal responses did not change significantly in either group, confirming that the visual stimulation must be concurrent with locomotion for enhancement (Fig. 4D).

Together, these observations indicate that stimulus-specific enhancement is dependent on a cortical state that is induced by locomotion and not merely on repeated exposure to the stimulus.

\section{Response enhancement measured in single cells}

To begin to understand cellular mechanisms of the stimulusspecific response enhancement observed in intrinsic signal imaging experiments, we examined changes in response properties of 
A

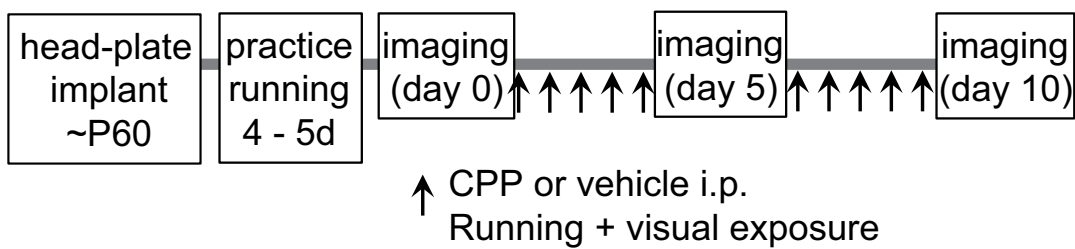
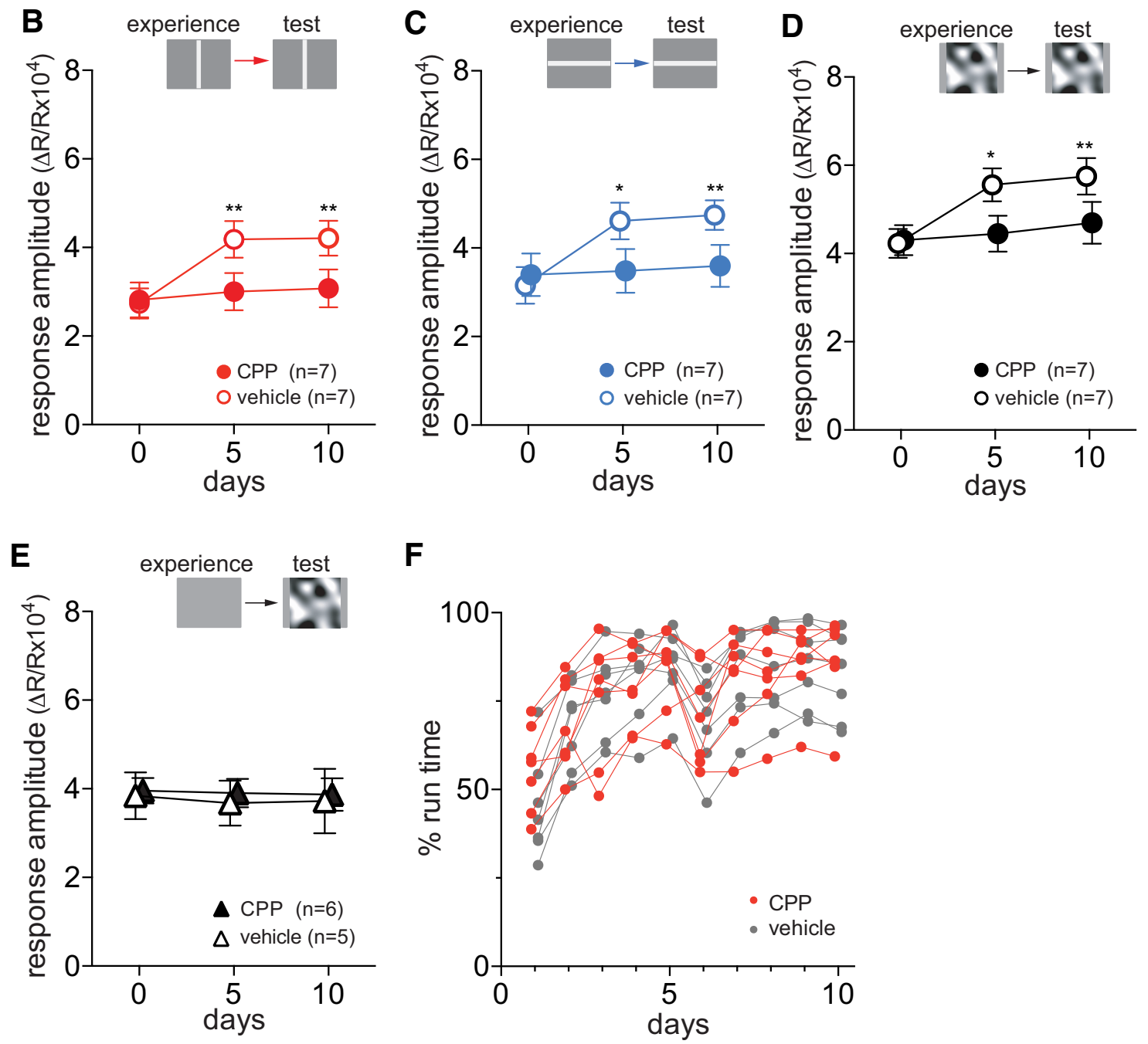

Figure 3. Response potentiation depends on NMDA receptor activation. $\boldsymbol{A}$, Experimental schedule. $\boldsymbol{B}-\boldsymbol{D}$, Changes in responses to drifting vertical bars $(\boldsymbol{B})$, to drifting horizontal bars $(\boldsymbol{C})$, or to contrast-modulated noise $(\boldsymbol{D})$ in mice that experienced same visual patterns during daily running. Closed circles and open circles represent CPP-treated $(n=7)$ and vehicle-treated $(n=7)$ animals, respectively. $E$, Lack of effects of partial NMDA receptor blockade on stability in response magnitude of intrinsic signals over the period of $10 \mathrm{~d}$ in animals that were exposed to an uniform $50 \%$ gray screen during daily running. $F$, Percentage of time that each mouse moved $>1 \mathrm{~cm} / \mathrm{s}$ on the Styrofoam ball during daily running plus VE in (PP-treated (red circles) and vehicle-treated (gray circles) groups shown in $\boldsymbol{B}$. Data in $\boldsymbol{B}-\boldsymbol{E}$ are presented as mean $\pm \mathrm{SEM}^{*} p<0.05 ;{ }^{* *} p<0.01$ compared with baseline (day 0 ) within the group (two-way ANOVA followed by multiple comparisons with Bonferroni correction).

individual neurons in layers $2 / 3$ of the primary visual cortex using two-photon imaging of $\mathrm{Ca}^{2+}$ signals. Two weeks after injecting AAV1-Syn-GCaMP6s stereotaxically into the primary visual cortex on $\sim \mathrm{P} 45$, we implanted the chamber for head fixation containing the imaging window centered the injection site, and then gave the mice 3-4 $\mathrm{d}$ of practice standing and running on the Styrofoam ball for $15 \mathrm{~min} / \mathrm{d}$. We then made baseline recordings of the calcium responses of many single cells to gratings drifting in 8 different directions while the mice were anesthetized. After an additional $2-3 \mathrm{~d}$, the mice were placed for 60 min daily on the floating Styrofoam ball while viewing one of three stimuli: gratings oriented at $45^{\circ}$ drifting back and forth (G45; two mice), drifting gratings oriented at $135^{\circ}$ (G135; two mice), or a blank (50\% gray) screen (control, two mice). After $5 \mathrm{~d}$ of running plus $\mathrm{VE}$, the calcium recordings were repeated so as to measure responses in the same cells that were studied at baseline (Fig. 5A).

Of the total of 838 cells that were identifiable in both baseline and postexposure recordings (control, 324; G45, 286; G135, 228 cells), we selected cells with peak $\Delta F / F \geq 0.25$ in both recordings as responsive cells for further analyses (control, 192; G45, 172; 


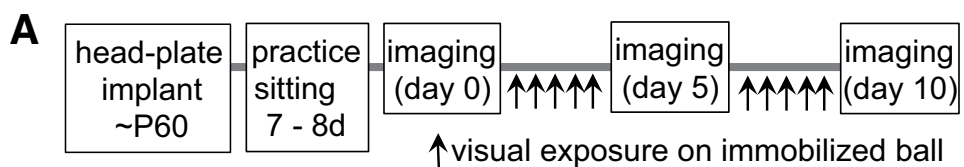

B

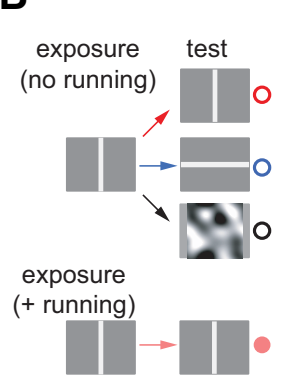

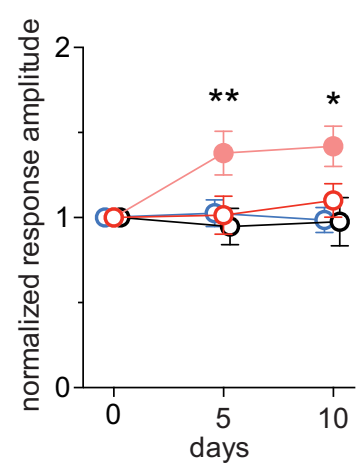
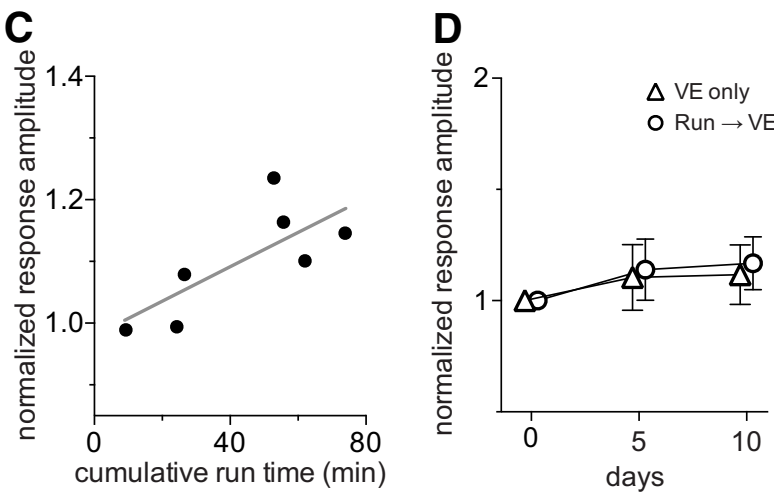

Figure 4. Restricting locomotion reduces stimulus-specific enhancement of response magnitude. $\boldsymbol{A}$, Experimental schedule. $\boldsymbol{B}$, Changes in response magnitudes in animals that viewed drifting vertical bars daily while on the Styrofoam ball, the movement of which was restricted. Intrinsic signal imaging was performed in each animal to measure cortical responses to three different visual stimuli, vertical bars (red), horizontal bars (blue), and contrast-modulated noise (black). The right panel shows change in response amplitude in animals that moved freely on the ball while viewing drifting vertical bars, shown in solid pink circles (data from Fig. 1C). Response amplitudes were normalized to baseline (day 0 ) and are shown as mean $\pm S D$. ${ }^{*} p<0.05$; ${ }^{* *} p<0.01$ between the free run group and restricted move group (two-way ANOVA followed by multiple comparisons with Bonferroni's correction). $C$, Change in response amplitude as a function of total duration of movement in animals that were placed on balls with restricted movement. Each point shows data from individual animals in $\boldsymbol{B}$. The $y$-axis represents normalized responses to drifting vertical bars (the exposed visual stimulus) at day 10 . The $x$-axis represents 10 day cumulative duration that the trackball was considered moving $\left(>1 \mathrm{~cm} / \mathrm{s} ; R^{2}=0.58 ;\right.$ slope, $0.0029 \pm 0.0011 ; 95 \% \mathrm{Cls}$, $4.39 \mathrm{e}^{-0.005}, 0.0057$; slope deviation from zero, $p=0.047$; least-squares linear regression). $\boldsymbol{D}$, Visual experience while not engaging in running did not enhance V1 responses. One group of animals was allowed to run freely on a floating Styrofoam ball while viewing a blank gray screen for $1 \mathrm{~h}$ daily, followed immediately by being returned to home cage and exposed to a drifting vertical bar for $1 \mathrm{~h}$, on day 1 through day 10 (run $\rightarrow \mathrm{VE} ; n=4$ ). Another group of mice was exposed to the same visual stimulus in the home cage without preceding running (VE only; $n=4)$. Visual exposure was done while the animals were placed in the housing cage, which was made of clear polycarbonate and surrounded by four monitors, one on each side, displaying the visual stimulus. Responses to the experienced stimulus (vertical bar) were recorded on day 0 (baseline), day 5 , and day 10 . Data are normalized to the baseline value and presented as mean \pm SD. Response magnitude on day 5 or day 10 was not significantly different from baseline in either group (two-way ANOVA).

G135, 166 cells). Figure $5 B-D$ shows examples of responses at baseline and postexposure in the control and G45 groups. The cell shown in Figure $5 B$ from a control animal had moderately tuned baseline responses that did not change in either amplitude or selectivity between the two recording sessions (O_prf, 140.1 vs 144.9 ; OSI, 0.40 vs 0.48 ; Gaussian fit peak, 0.44 vs 0.49 ; baseline vs postexposure). The cell shown in Figure $5 C$ from a G45 animal had moderately tuned baseline responses (OSI, 0.38) similar to that of a control cell shown in Figure 5B. Its postexposure responses to the exposed orientation (O_exp) was increased (0.197 vs 0.406 ) with little change in responses to the orthogonal orientation ( 0.198 vs 0.163 ) or overall responsiveness ( 0.236 vs 0.225 ; $\Delta F / F$ averaged for all orientations), resulting in a shift of its $O_{-} p r f$ toward the O_exp (1.4 vs 34.4). Another example cell from the same G45 mouse, shown in Figure $5 D$, was initially highly selective for the O_exp at baseline (O_prf, 46.6; OSI, 0.76), and the responses after exposure to that orientation were increased $(0.78$ vs 1.35) with little change in responses to the orthogonal orientation ( 0.16 vs 0.20$)$, resulting in further sharpening of orientation tuning (O_prf, 43.9; OSI, 0.82).

On average, cells in running plus VE groups significantly increased their responses to the exposed orientations ( $p<0.01$; oneway ANOVA followed by multiple comparisons with Bonferroni corrections), while their responses to the orthogonal orientations were unchanged ( $p>0.05$ vs control; Figs. $6 A-C$ ). Cells in control animals showed no statistically significant changes in responses to either orientation (Fig. $6 A-C$ ).

Despite the prominent increase in average responses to the exposed orientations, changes in individual cells in the experimental groups varied widely. For both G45 and G135 experimental groups, the change in response to $O \_\exp$ depended strongly on each cells' O_prf at baseline (Fig. 6D), whereas cells in control mice showed negligible changes in response magnitudes to the two experimental orientations between recording sessions (Fig. $6 E$ ). The cells initially selective for orientations closer to $O \_\operatorname{exps}$ in the experimental mice showed much larger increases in responses to that orientation than did other cells (Fig. $6 F ; R^{2}=$ 0.35 , least-squares linear regression; $R^{2}=0.40$ for nonlinear fit exponential one-phase decay).

These findings suggest that the response to a particular stimulus is enhanced by locomotion to an extent that depends on how well the neuron responds to that stimulus at baseline. To test this notion, we plotted the degree of enhancement as a function of the baseline responses (Fig. 7). In both experimental groups there was a highly significant relationship between baseline response to the exposed stimulus and enhancement. Responses to the stimuli that were not exposed were not enhanced.

As a result of increase in the response magnitude to the exposed orientation with little change in responses to other orientations, the preferred orientation of cells whose baseline preferred orientations were close to the one exposed shifted toward the exposed orientation (Fig. $8 A, B, D, E$, note the flattening of the preexposure vs postexposure curves near $O \_$exp in the G45 and G135 groups). Cells in control animals showed no significant changes in their preferred orientations (Fig. $8 C-E$ ). Figure 8, $F$ and $G$, compares the shifts in $O_{-} p r f$ between control and experimental groups.

The OSI, calculated as the ratio of response at the preferred to that at the orthogonal orientation, is an additional measure to describe orientation tuning. While distributions of OSI were indistinguishable between groups at baseline (Fig. $8 \mathrm{H}$ ), the OSIs of experimental animals were slightly shifted toward higher values after exposure because of the changes in response amplitudes 
A

\begin{tabular}{|c|c|}
\hline $\begin{array}{l}\text { 〜P45 } \\
\text { AAV-hsyn1- } \\
\text { GCaMP6s } \\
\text { injection }\end{array}$ & $\begin{array}{l}\text { P60 } \\
\text { Imaging } \\
\text { chamber } \\
\text { implant }\end{array}$ \\
\hline
\end{tabular}

\section{Practice \\ baseline} running 3-4d imaging post-exposure imaging

B
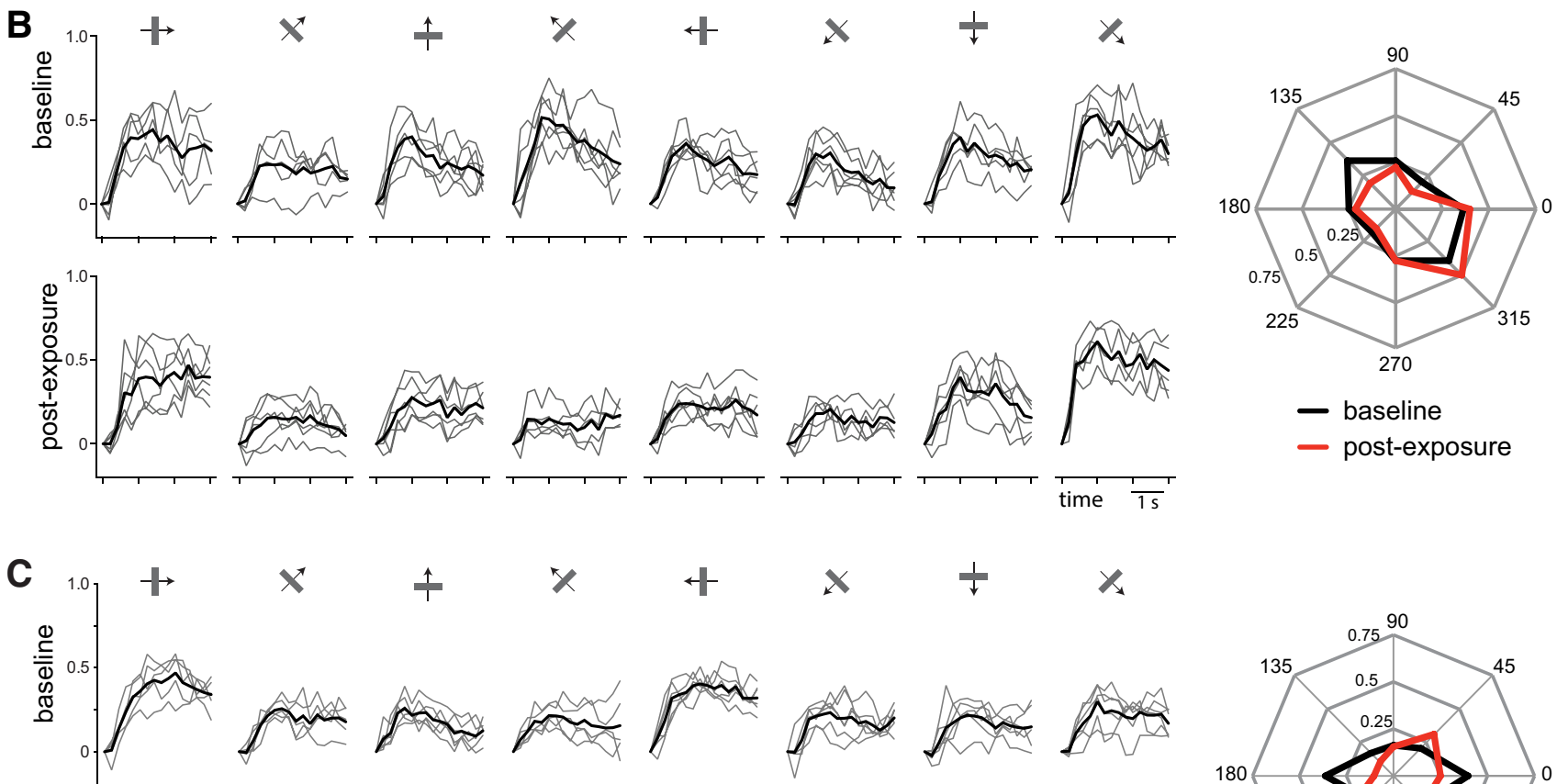

$x+1$
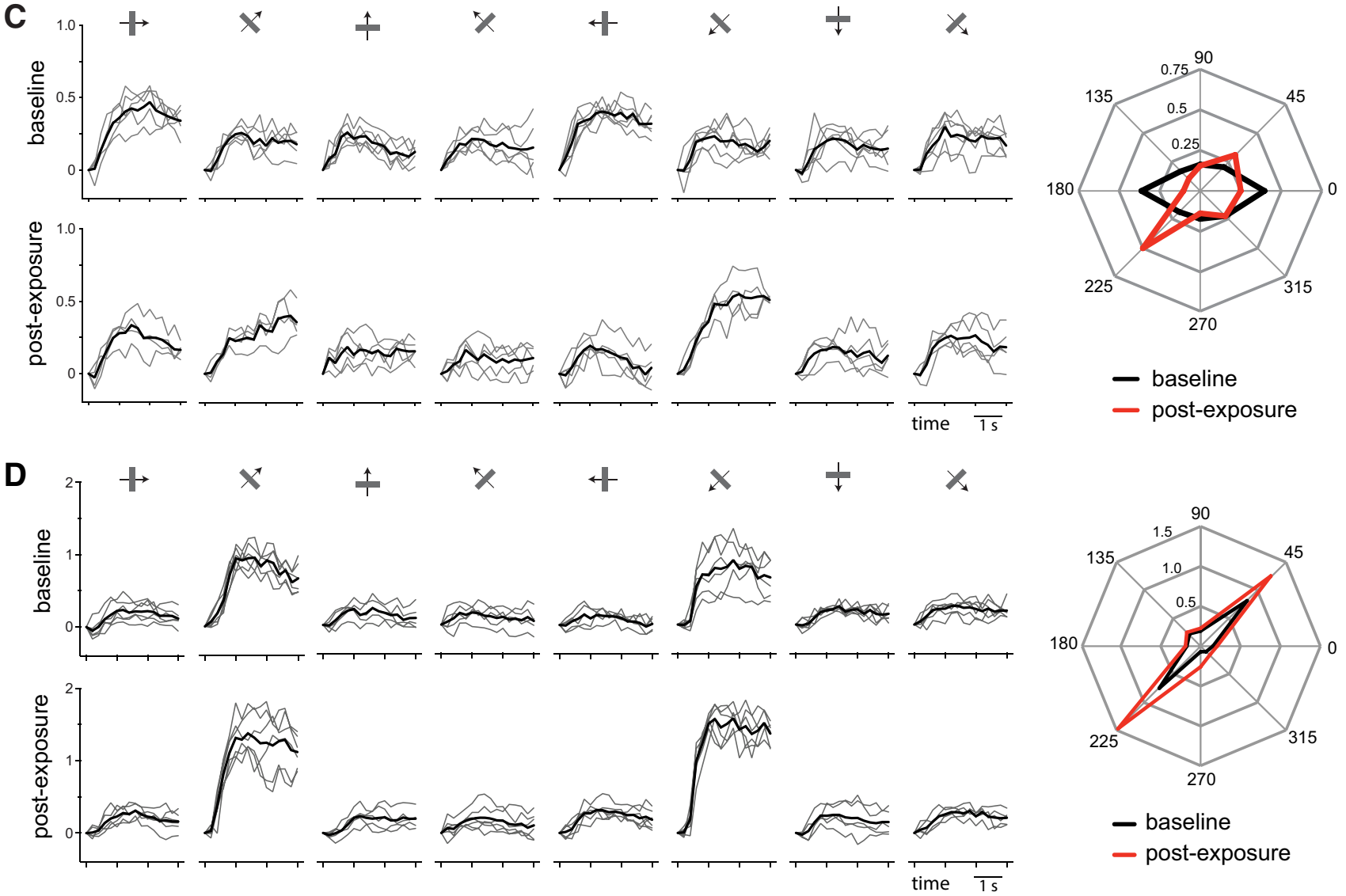

- baseline

- post-exposure

Figure 5. Tracking changes of calcium responses in individual cells. $A$, Experimental schedule. $\boldsymbol{B}-\boldsymbol{D}$, Examples of calcium signal traces in response to drifting gratings of eight different directions in a cell in a control animal ( $\boldsymbol{B}$ ) and two cells in an experimental animal ( $\boldsymbol{C}, \boldsymbol{D} ;$ both are in the $G 45$ group). Left, Top panels, Baseline recordings. Bottom, Postexposure recordings. Thin gray lines mark individual trials. Black lines show means of five to six individual trials. Right, Polar plots of averaged responses in baseline (black) and postexposure (red) recordings. Responses to each direction were averaged over the last $2 \mathrm{~s}$ of stimulus presentation.

(Fig. $8 I, p=0.002$, control vs $\mathrm{G} 45 ; p=0.004$, control vs $\mathrm{G} 135$; Kolmogorov-Smirnov test). In cells initially selective for orientations within $50^{\circ}$ of $O \_$exp, the magnitude of shift in $O \_p r f$ was inversely correlated with the baseline OSI (Fig. $8 \mathrm{~J} ; R^{2}=0.18$, least-squares linear regression). In this population of cells, increase in OSI was inversely correlated with the difference between baseline $O \_p r f$ and $O \_\exp$ (Fig. $8 K ; R^{2}=0.28$, least-squares linear regression). In cells with baseline $O \_p r f$ further than $50^{\circ}$ from 
A

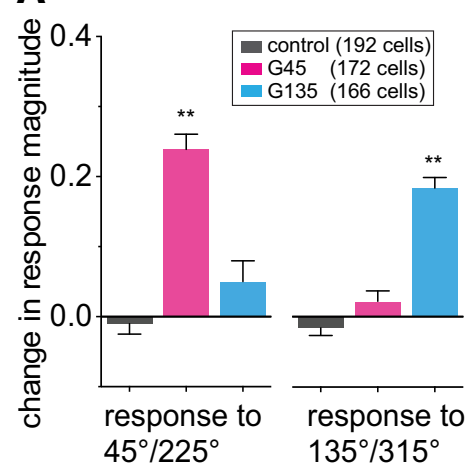

D

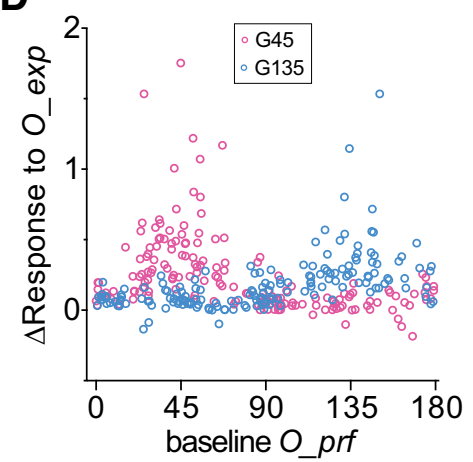

B

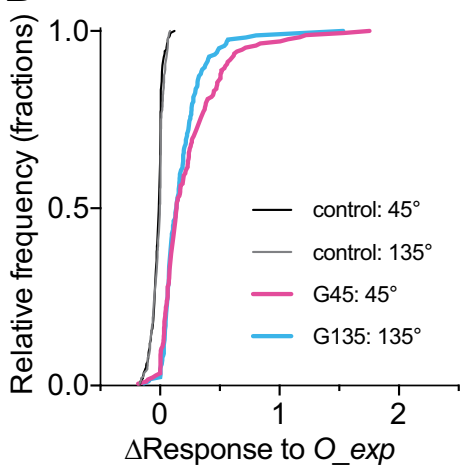

E

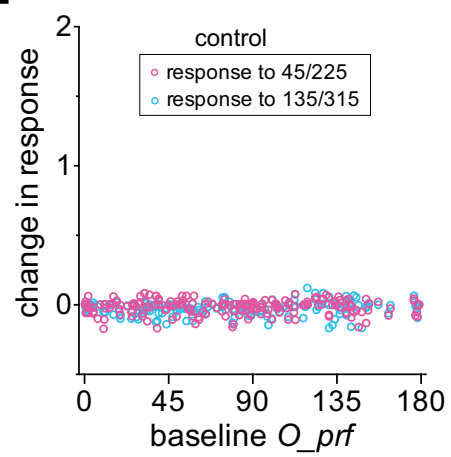

C

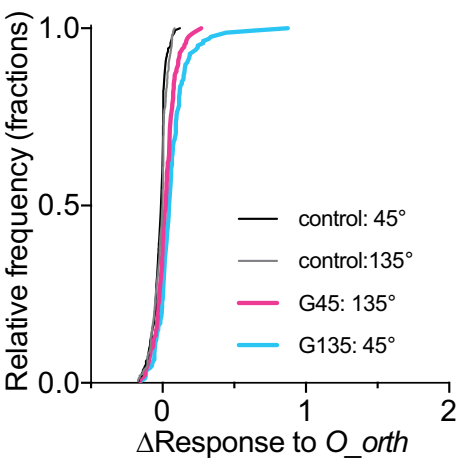

$\mathbf{F}$

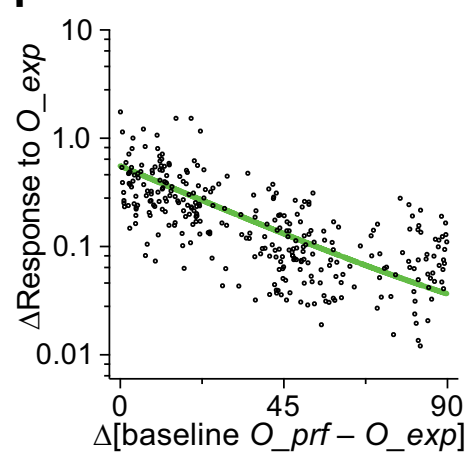

Figure 6. Changes in calcium response magnitudes after running plus visual exposure. $A$, Changes in calcium signals in response to gratings of the exposed orientation and the orthogonal orientation. Bars represent mean \pm SEM. ${ }^{* *} p<0.001$, compared with the respective control group (one-way ANOVA followed by multiple comparisons with Bonferroni's correction). $\boldsymbol{B}, \boldsymbol{C}$, Cumulative frequency distributions of changes in response magnitude to the exposed orientation during running $\left(0 \_\right.$exp; $\left.\boldsymbol{B}\right)$ and the orientation orthogonal to 0 _exp $\left(0 \_\right.$orth, $\boldsymbol{C}$. $\boldsymbol{D}, \mathbf{C}$. responses to orientations that were exposed during locomotion (0_exp), plotted against each cell's baseline preferred orientation. Each circle represents simple difference in response magnitudes between postexposure and baseline in a single cell. $\boldsymbol{E}$, Differences in responses to gratings at $45^{\circ} / 225^{\circ}$ and $135^{\circ} / 315^{\circ}$ between the first (baseline) and the second (postsession) recordings plotted against each cell's baseline 0 _prf in the control group. Each circle represents the simple difference in response magnitudes between postsession and baseline in a single cell. $\boldsymbol{F}$, Changes in responses to 0 _exp, shown in $\boldsymbol{D}$, were replotted to the distance of each cell's baseline $0 \_$prffrom 0 _exp. Data from two experimental groups were pooled. The green line represents one phase decay fit $\left(R^{2}=0.399\right)$.

O_exp, there was no relation between baseline OSI and shifts in preferred orientation (Fig. $8 \mathrm{~L}$ ).

These findings reveal that single cells that are driven well by the stimulus presented during locomotion dramatically increase their responses to that stimulus, on average by $\sim 20 \%$, and many by $50 \%$ or more, with little or no change in other cells (Fig. $6 A, B$ ). These changes in response magnitude have the effect of slightly shifting the preferred orientations of those cells toward the one exposed, at least as assessed from fits to tuning curves derived from responses to stimuli presented in $45^{\circ}$ steps. Responses of neurons in control animals exposed to a gray screen during locomotion are, as expected, stable in both magnitude and selectivity (Figs. 6E, 8C). Results from single cell analysis are thus consistent with those measured using intrinsic signals: response enhancement by locomotion is stimulus specific.

\section{Discussion}

Many experiments have found that responses in the primary visual cortex in adult mammals are stable over long periods. In the present study, using noninvasive repeated imaging of intrinsic signals, we found that the daily exposure of adult mice to highcontrast visual stimuli in animals allowed to move freely on a spherical treadmill enhanced the responsiveness of V1 to those stimuli, leaving responses to other stimuli unchanged. This enhancement depended on NMDA receptor activation. Most strikingly, the enhancement to the specific stimuli presented depended on the animals' locomotion, presumably reflecting the high-gain state into which locomotion places mouse V1 (Niell and Stryker, 2010). Repeated imaging of $\mathrm{Ca}^{2+}$ signals in single cells confirmed the stimulus specificity of the enhancement of V1 responses at the cellular level. They revealed that $\mathrm{Ca}^{2+}$ responses to the orientation that was viewed by animals during running were increased, while the responses to other orientations were not, a change that produced an attractive shift in preferred orientation toward the one that was viewed.

\section{A circuit responsible for stimulus-specific enhancement during locomotion}

The present finding that the cortical state produced by locomotion is required for enhancement is consistent with our previous observations that recovery of V1 responses from prolonged monocular deprivation was greatly augmented by high-contrast visual stimulation while animals were engaged in locomotion (Kaneko and Stryker, 2014). This recovery depended on a subcorticocortical circuit that increases responsiveness of mouse V1 (Fu et al., 2014; Lee et al., 2014). The circuit originates in ascending projections of the midbrain locomotor region (MLR) to the horizontal limb of the nucleus of the diagonal band of Broca, which sends cholinergic projections to activate vasoactive intestinal peptide (VIP)-containing cells in V1 during locomotion. The VIP-containing cells inhibit somatostatin (SST)-expressing GABAergic cells, disinhibiting the excitatory neurons and increasing their responses (Pfeffer et al., 2013; Fu et al., 2014). In general terms, such changes in excitation/inhibition balance are expected to enhance activity-dependent plasticity in adult 
A

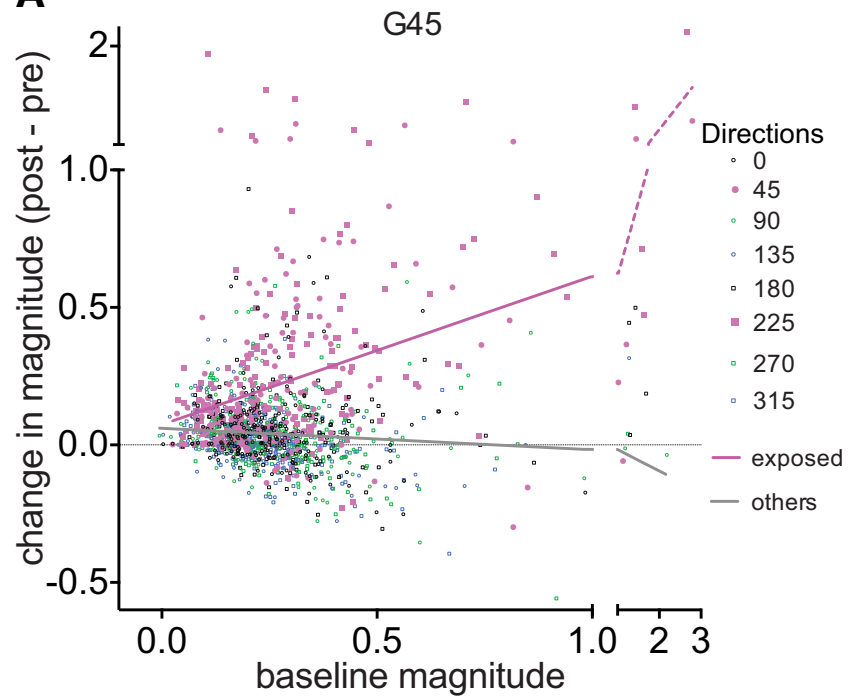

B

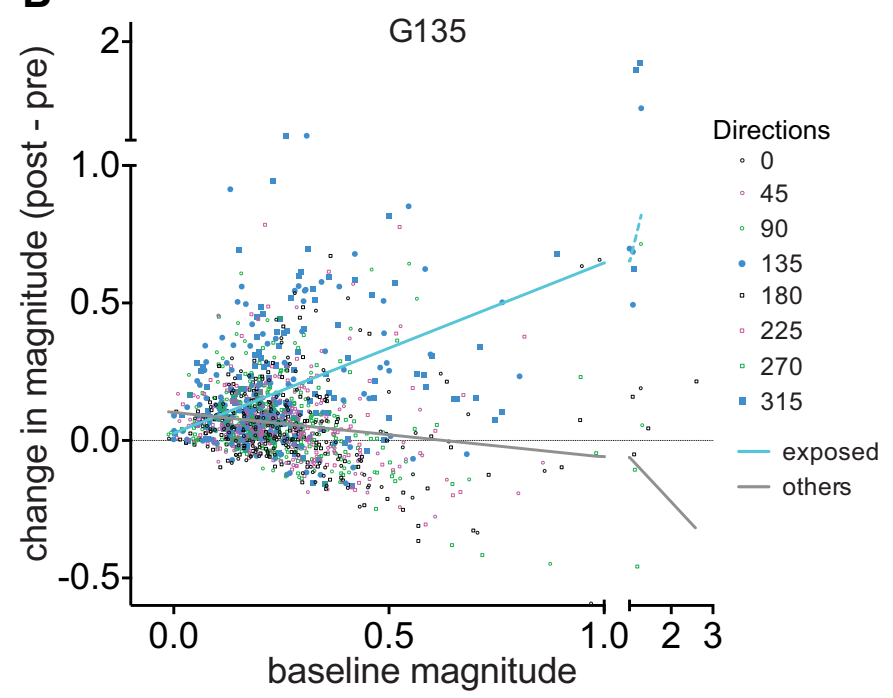

C

\begin{tabular}{llcrrl}
\hline Group & direction & \multicolumn{1}{c}{ slope } & \multicolumn{2}{c}{ slope $95 \% \mathrm{Cl}$} & $\mathrm{R}^{2}$ \\
\hline G45 & exposed & $0.540 \pm 0.053$ & 0.436 & 0.644 & 0.234 \\
G45 & others & $-0.077 \pm 0.023$ & -0.122 & -0.033 & 0.011 \\
\hline G135 & exposed & $0.619 \pm 0.060$ & 0.501 & 0.737 & 0.243 \\
G135 & others & $-0.163 \pm 0.024$ & -0.210 & -0.115 & 0.043
\end{tabular}

Figure 7. Relationship between baseline $\mathrm{Ca}^{2+}$ responses and change in response magnitudes at each direction of drifting grating stimuli. $\boldsymbol{A}, \boldsymbol{B}, \mathrm{Data}$ from each experimental group were plotted separately ( $\boldsymbol{A}, \mathrm{G} 45$ group; $\boldsymbol{B}, \mathrm{G} 135$ group). Lines represent least squares linear regression, analyzed for the exposed two directions and other six directions separately. $\boldsymbol{C}$, Statistical data for linear regression. All slopes showed statistically significant deviation from zero $(p<0.0001)$.

V1 (Harauzov et al., 2010; for review, see Bavelier et al., 2010 and Takesian and Hensch 2013). Experiments inducing loss of function (using tetanus toxin) and gain of function (using optogenetic activation) of VIP-containing cells in mouse V1 revealed that the activity of the VIP-SST disinhibitory circuit was necessary and sufficient in adult V1 to facilitate recovery from amblyopia caused by prolonged $\mathrm{MD}$ and to enhance ocular dominance changes by short periods of MD that would otherwise have been ineffective (Fu et al., 2015). It therefore is likely that the same disinhibitory circuit is responsible for the stimulus-specific enhancement in V1 responses that we report in the present study.

How might the engagement of this disinhibitory circuit with its transient resetting of excitation/inhibition balance produce the stimulus-specific enhancement of $\mathrm{V} 1$ responses? The present findings from longitudinal $\mathrm{Ca}^{2+}$ imaging of single cells may shed light on the cellular mechanisms. On average, considered as a single population, $\mathrm{V} 1$ neurons showed increased $\mathrm{Ca}^{2+}$ responses to the experienced orientation (Fig. 6A), while responses to nonexperienced orientations were unchanged, consistent with the result at the whole $\mathrm{V} 1$ level observed in intrinsic signal imaging. However, the changes at the individual cell level were different from cell to cell. In particular, nearly all of the increase in response to the experienced orientation was in cells in which the baseline preferred orientation was close to the experienced orientation and not in those in which preferred orientation was different (Fig. 6D). Although the mouse lacks orientation columns, L2/3 pyramidal neurons in V1 with similar orientation selectivity preferentially form synapses with one another; that is,
V1 is organized into subnetworks defined by anatomical connectivity among cells that have similar responses (Ko et al., 2011; Cossell et al., 2015; Lee et al., 2016). Viewing stimuli of a specific orientation during locomotion drives the orientation-specific subnetwork to increased firing because of disinhibition. Such an increase in synaptic activity would be expected to produce Hebbian plasticity specifically within that subnetwork, resulting in stronger connections among the cells that would continue to drive stronger responses even after the disinhibition was no longer present. Note that the changes in our experimental measurements using both intrinsic signal imaging and calcium imaging reflect the plasticity that was induced by the MLR-VIP-SST disinhibitory circuit, but they do not result from the activity of this circuit during the measurements, which were made in anesthetized animals in which the circuit was not active.

In neurons that showed an increase in $\mathrm{Ca}^{2+}$ responses to the experienced orientation with unchanged responses to other orientations, the measured preferred orientation consequently shifted toward the experienced orientation. This finding may reflect in part the fitting of tuning curves to coarsely sampled responses, at $45^{\circ}$ steps in this experiment.

\section{Previous reports of enhancement}

Our results from intrinsic signal recordings are generally in agreement with the previous reports in which recordings were made using VEPs (Frenkel et al., 2006; Cooke and Bear 2010), including observations of stimulus specificity, requirement for NMDA receptor activation, persistence of enhancement after the 
A

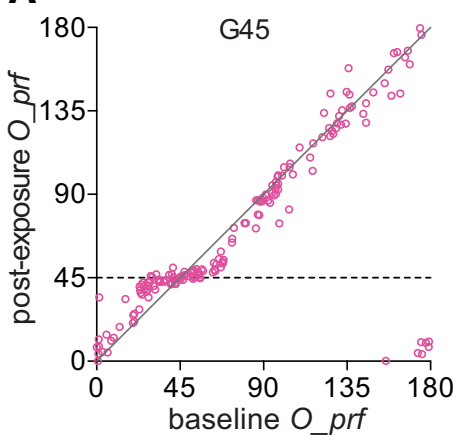

D

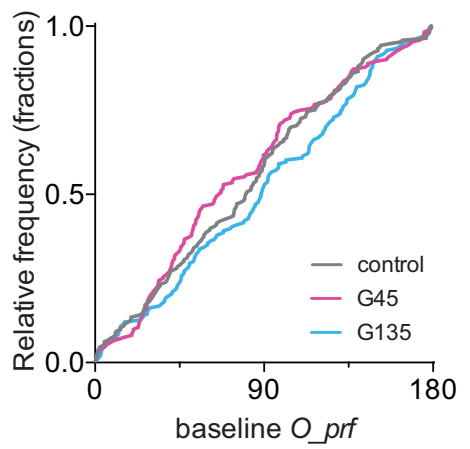

G

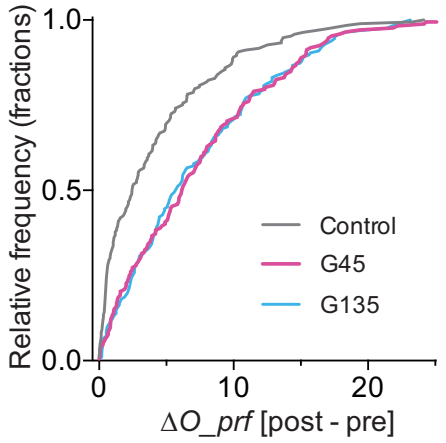

J

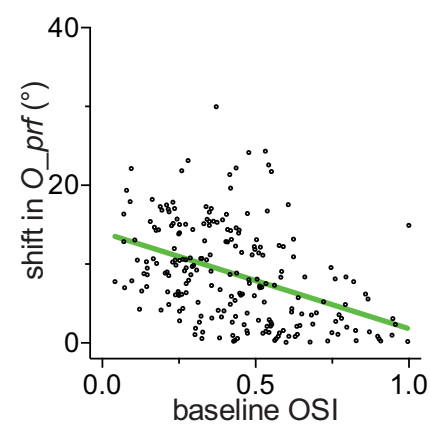

B

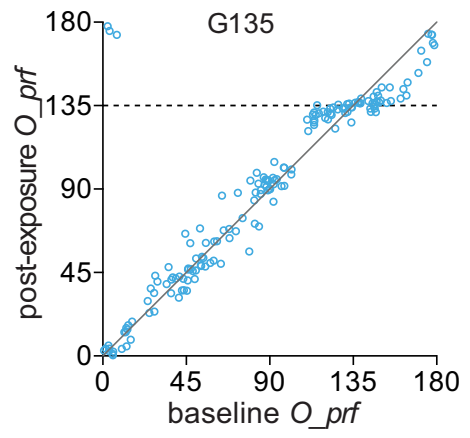

E

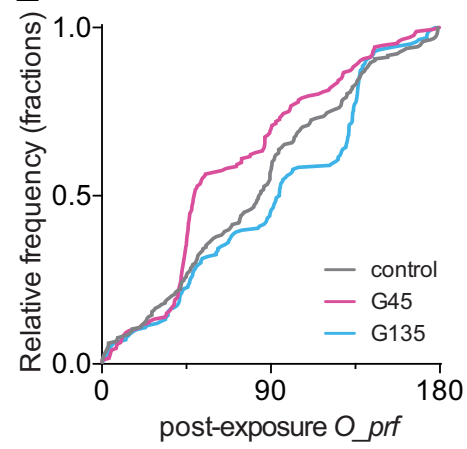

H

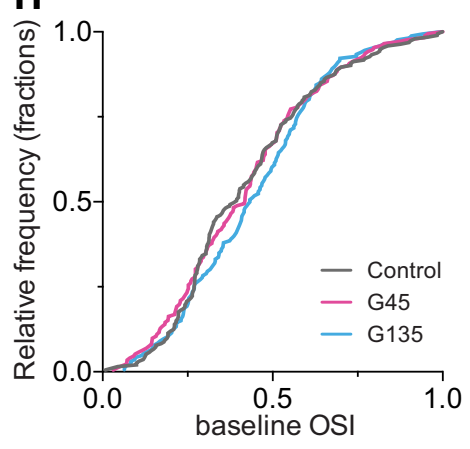

K

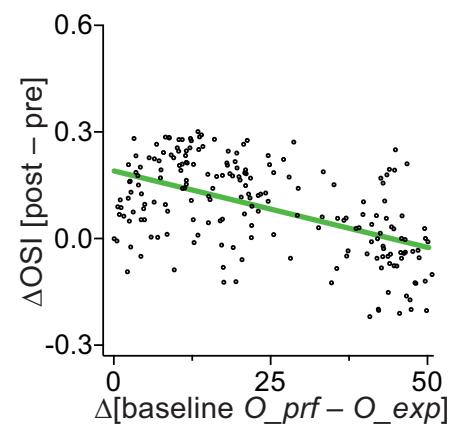

C

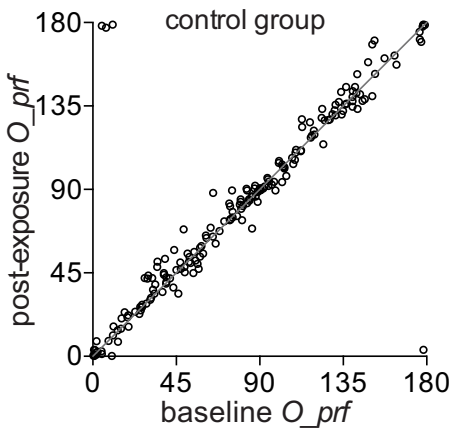

F
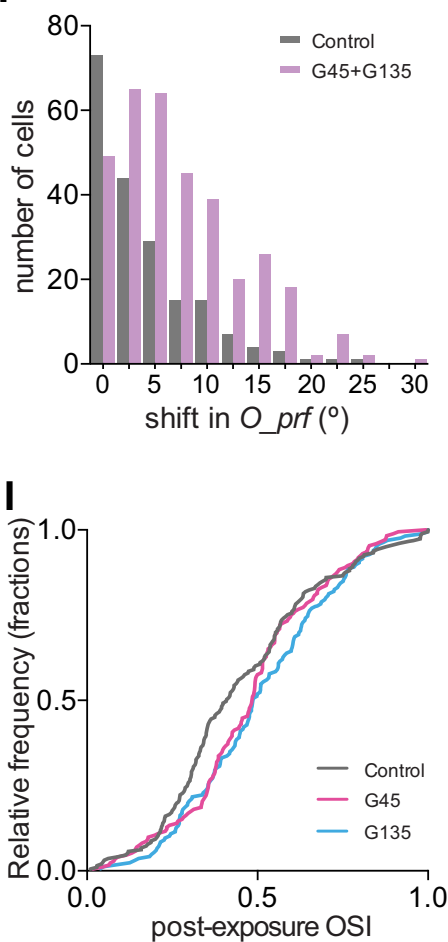

L

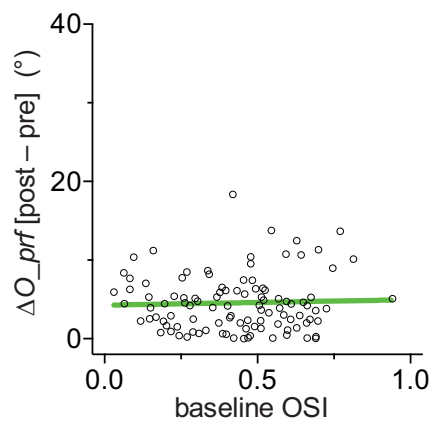

Figure 8. Changes in preferred orientation and orientation selectivity after running plus visual exposure. $A-C$, Preferred orientation in individual cells at baseline ( $x$-axis) and after exposure ( $y$-axis) in the $G 45(\boldsymbol{A}), \mathrm{G} 135(\boldsymbol{B})$, and control (C) groups. $\boldsymbol{D}$, Cumulative frequency distribution of preferred orientations at baseline. $\boldsymbol{E}$, Cumulative frequency distribution of $0 \_p r f$ after exposure to specific orientations of drifting gratings during daily running. $F$, Frequency distributions of shift in $0 \_$prf, summarized from data shown in $A-C$. Data from two experimental groups were pooled. $p<$ 0.001 between control and experimental groups (Kolmogorov-Smirnov test). $\mathbf{G}$, Cumulative frequency distribution of shift in 0 _prf in individual cells. $\boldsymbol{H}$, Cumulative frequency distribution of orientation selectivity at baseline. I, Cumulative frequency distribution of OSI after the exposure to specific orientations of drifting gratings during daily running. $J$, Inverse correlation between baseline OSI and shift in 0_prf in experimental groups. The green line represents linear regression $\left(R^{2}=0.18\right.$; slope, $-12.21 \pm 1.78 ; 95 \%$ Cls, $-15.71,-8.72$; slope deviation from zero, $p<$ $0.0001) . K$, Increase in orientation selectivity when the cells' baseline $0 \_$prf was closer to $0 \_$exp. The green line represents linear regression $\left(R^{2}=0.28 ;\right.$ slope, $-0.0043 \pm 0.0005 ; 95 \%$ Cls, $-0.0053,-0.0033$; slope deviation from zero, $p<0.0001)$. L, Shift in $0 \_$prf had no relationship to baseline 0 SI in cells in which baseline $0 \_$prf were $>50^{\circ}$ apart from the exposed orientations $\left(R^{2}=0.0015 ;\right.$ slope, $0.703 \pm 1.807 ; 95 \% \mathrm{Cls},-2.89,4.29$; slope deviation from zero, $p=0.698$, least-squares linear regression). For analyses in $J$ and $\boldsymbol{K}$, we selected cells in which baseline $0 \_p r f$ was within $50^{\circ}$ from $0 \_$exp and pooled G45 and G135 $(n=199)$. 
sessions of visual stimulation were ended, and the degree of enhancement in mice older than P60. However, a critical difference between the present study using intrinsic signal and the earlier VEP studies is that in the latter animals were restrained during the daily exposure to visual stimuli, whereas we found no significant enhancement when the animals' movements were restricted.

Several factors may contribute to this difference. First, different techniques were used to measure responsiveness. Intrinsic signal imaging used in this study is completely noninvasive and has been shown to produce a stable readout of visual cortical responsiveness over weeks (Kaneko and Stryker 2014). In contrast, chronic VEP recording requires electrode implantation right into the brain tissue at the center of interest, which could induce inflammatory responses including reactive astrocytes. Such disruptions can result in an increase in excitability of pyramidal cells resulting from dysfunction in astrocytes for microenvironment homeostasis and/or maintenance of GABAergic inhibition (for review, see Robel and Sontheimer, 2016). This increased excitation-inhibition balance may induce an abnormally high degree of plasticity in the adult brain (for review, see Bavelier et al., 2010).

Second, the VEP studies focused on layer 4 (L4), whereas the present study's intrinsic optical signals reflect activity in L2/3 more strongly than in L4, with a significant contribution from L4 (Trachtenberg et al., 2000), and our chronic $\mathrm{Ca}^{2+}$ imaging was performed entirely on L2/3 cells. Perceptual learning has been shown to have different effects on L2/3 and L4 pyramidal neurons in mouse V1 (Makino and Komiyama 2015). L2/3 neurons acquired a new response pattern suggestive of anticipatory response, while L4 neurons did not. This change in L2/3 was accompanied by increased excitatory drive from of top-down inputs. In rats, L2/3 excitatory cells in S1 showed a tonic activation pattern that was longer in duration and higher in magnitude than that in L4 cells during active tactile discrimination, presumably also resulting from the influence by top-down inputs (Krupa et al., 2004). Similarly, after visual discrimination training in rhesus monkeys, sharpening of orientation tuning curve was observed in supragranular layer but not in L4 (Schoups et al., 2001).

In addition to laminar differences, intracortical microcircuits that participate in the enhancement of responses in L4 may be distinct from the locomotion-induced response enhancement that we observed. A recent report implicated the activity of parvalbumin-expressing GABAergic cells in L4 enhancement (Kaplan et al., 2016). In contrast, as described above, a disinhibitory circuit comprised of VIP-containing cells and SST-expressing cells plays a key role in control of the gain of visual responses and in facilitation of plasticity by locomotion in adult visual cortex, whereas PV neurons do not show consistent responses to locomotion (Fu et al., 2014, 2015).

\section{Outstanding questions about the role of locomotion and cortical plasticity}

In the present experiment, the changes that were observed depended on locomotion. However, locomotion may be just one of many ways of activating the same circuit to enhance plasticity. While using locomotion to activate VIP-containing cells in mouse V1 is particularly convenient for our experiments, recent findings indicate that "top-down" inputs from frontal cortex project to L1 of V1 to activate a similar disinhibitory circuit that almost certainly includes the same VIP-containing cells during perceptual learning (Makino and Komiyama, 2015; Zhang et al., 2016). This idea is also consistent with many previous observations that responses in V1 were enhanced and visual behavior tasks were improved by pairing visual stimulation with manipulations that activate cholinergic inputs, such as application of cholinergic agonists and electrical or optogenetic activation of the basal forebrain (for review, see Gu, 2003; Kang et al., 2014). Some recent studies have found that pupil dilation, often used as a measure of arousal, can be associated with changes in cortical responses similar to those produced by locomotion, but arousal is also activated by different systems with different effects on cortical activity (Reimer et al., 2014; Vinck et al., 2015).

We do not know how general the stimulus-specific plasticity induced in V1 by locomotion is, but preliminary reports do suggest an effect in humans (Lunghi and Sale, 2015; Bullock et al., 2016).

\section{References}

Bavelier D, Levi DM, Li RW, Dan Y, Hensch TK (2010) Removing Brakes on adult brain plasticity: From molecular to behavioral interventions. J Neurosci 30:14964-14971. CrossRef Medline

Brainard DH (1997) The psychophysics toolbox. Spat Vis 10:433-436. CrossRef Medline

Bullock T, Elliott JC, Serences JT, Giesbrecht B (2016) Acute exercise modulates feature-selective responses in human cortex. J Cogn Neurosci 29: 605-618. Medline

Cooke SF, Bear MF (2010) Visual experience induces long-term potentiation in the primary visual cortex. J Neurosci 30:16304-16313. CrossRef Medline

Cossell L, Iacaruso MF, Muir DR, Houlton R, Sader EN, Ko H, Hofer SB, Mrsic-Flogel TD (2015) Functional organization of excitatory synaptic strength in primary visual cortex. Nature 518:399-403. CrossRef Medline

Espinosa JS, Stryker MP (2012) Development and plasticity of the primary visual cortex. Neuron 75:230-249. CrossRef Medline

Frenkel MY, Sawtell NB, Diogo AC, Yoon B, Neve RL, Bear MF (2006) Instructive effect of visual experience in mouse visual cortex. Neuron 51:339-349. CrossRef Medline

Fu Y, Tucciarone JM, Espinosa JS, Sheng N, Darcy DP, Nicoll RA, Huang ZJ, Stryker MP (2014) A cortical disinhibitory circuit for gain control by behavioral state. Cell 156:1139-1152. CrossRef Medline

Fu Y, Kaneko M, Tang Y, Alvarez-Buylla A, Stryker MP (2015) A cortical disinhibitory circuit for enhancing adult plasticity. Elife 4:e05558. Medline

Gilbert CD, Li W (2012) Adult visual cortical plasticity. Neuron 75:250264. CrossRef Medline

Greifzu F, Pielecka-Fortuna J, Kalogeraki E, Krempler K, Favaro PD, Schlüter OM, Löwel S (2014) Environmental enrichment extends ocular dominance plasticity into adulthood and protects from stroke-induced impairements of plasticity. Proc Natl Acad Sci US A 111:1150-1155. CrossRef Medline

Gu Q (2003) Contribution of acetylchoine to visual cortex plasticity. Neurobiol Learn Mem 80:291-301. CrossRef Medline

Harauzov A, Spolidoro M, DiCristo G, De Pasquale R, Cancedda L, Pizzorusso T, Viegi A, Berardi N, Maffei L (2010) Reducing intracortical inhibition in the adult visual cortex promotes ocular domimance plasticity. J Neurosci 30:361-371. CrossRef Medline

Kalatsky VA, Stryker MP (2003) New paradigm for optical imaging: temporally encoded maps of intrinsic signal. Neuron 38:529-545. CrossRef Medline

Kaneko M, Stellwagen D, Malenka RC, Stryker MP (2008) Tumor necrosis factor-alpha mediates one component of competitive, experiencedependent plasticity in developing visual cortex. Neuron 58:673-680. CrossRef Medline

Kaneko M, Stryker MP (2014) Sensory experience during locomotion promotes recovery of function in adult visual cortex. Elife 3:e02798. Medline

Kang JI, Huppé-Gourgues F, Vaucher E (2014) Boosting visual cortex function and plasticity with acetylcholine to enhance visual perception. Front Syst Neurosci 8:172. Medline

Kaplan ES, Cooke SF, Komorowski RW, Chubykin AA, Thomazeau A, Khibnik LA, Gavornik JP, Bear MF (2016) Contrasting roles for parvalbuminexpressing inhibitory neurons in two forms of adult visual cortical plasticity. Elife 5:e11450. Medline

Karmarkar UR, Dan Y (2006) Experience-dependent plasticity in adult visual cortex. Neuron 52:577-585. CrossRef Medline

Ko H, Hofer SB, Pichler B, Buchanan KA, Sjöström PJ, Mrsic-Flogel TD 
(2011) Functional specificity of local synaptic connections in neocortical networks. Nature 473:87-91. CrossRef Medline

Krupa DJ, Wiest MC, Shuler MG, Laubach M, Nicolelis MA (2004) Layerspecific somatosensory cortical activation during active tactile discrimination. Science 304:1989-1992. CrossRef Medline

Lee AM, Hoy JL, Bonci A, Wilbrecht L, Stryker MP, Niell CM (2014) Identification of a brainstem circuit regulating visual cortical state in parallel with locomotion. Neuron 83:455-466. CrossRef Medline

Lee WC, Bonin V, Reed M, Graham BJ, Hood G, Glattfelder K, Reid RC (2016) Anatomy and function of an excitatory network in the visual cortex. Nature 532:370-374. CrossRef Medline

Lunghi C, Sale A (2015) A cycling lane for brain rewiring. Curr Biol 25: R1122-R1123. CrossRef Medline

Makino H, Komiyama T (2015) Learning enhances the relative impact of top-down processing in the visual cortex. Nat Neurosci 18:1116-1122. CrossRef Medline

Maya Vetencourt JF, Sale A, Viegi A, Baroncelli L, De Pasquale R, O'Leary OF, Castrén E, Maffei L (2008) The antidepressant fluoxetine restores plasticity in the adult visual cortex. Science 320:385-388. CrossRef Medline

Medini P (2014) Experience-dependent plasticity of visual cortical microcircuits. Neuroscience 278:367-384. CrossRef Medline

Niell CM, Stryker MP (2008) Highly selective receptive fields in mouse visual cortex. J Neurosci 28:7520-7536. CrossRef Medline

Niell CM, Stryker MP (2010) Modulation of visual responses by behavioral state in mouse visual cortex. Neuron 65:472-479. CrossRef Medline

Ohki K, Chung S, Ch'ng YH, Kara P, Reid RC (2005) Functional imaging with cellular resolution reveals precise micro-architecture in visual cortex. Nature 433:597-603. CrossRef Medline

Pelli DG (1997) The VideoToolbox software for visual psychophysics: transforming numbers into movies. Spat Vis 10:437-442. CrossRef Medline

Perini R, Bortoletto M, Capogrosso M, Fertonani A, Miniussi C (2016) Acute effects of aerobic exercise promote learning. Sci Rep 6:25440. CrossRef Medline
Pfeffer CK, Xue M, He M, Huang ZJ, Scanziani M (2013) Inhibition of inhibition in visual cortex: the logic of connections between molecularly distinct interneurons. Nat Neurosci 16:1068-1076. CrossRef Medline

Reimer J, Froudarakis E, Cadwell CR, Yatsenko D, Denfield GH, Tolias AS (2014) Pupil fluctuations track fast twitching of cortical states during quiet wakefulness. Neuron 84:355-362. CrossRef Medline

Robel S, Sontheimer H (2016) Glia as drivers of abnormal neuronal activity. Nat Neurosci 19:28-33. CrossRef

Sato M, Stryker MP (2008) Distinctive features of adult ocular dominance plasticity. J Neurosci 28:10278-10286. CrossRef Medline

Sawtell NB, Frenkel MY, Philpot BD, Nakazawa K, Tonegawa S, Bear MF (2003) NMDA-receptor dependent ocular dominance plasticity in adult visual cortex. Neuron 38:977-985. CrossRef Medline

Schoups A, Vogels R, Qian N, Orban G (2001) Practicing orientation identification improves orientation coding in V1 neurons. Nature 412:549553. CrossRef Medline

Southwell DG, Froemke RC, Alvarez-Buylla A, Stryker MP, Gandhi SP (2010) Cortical plasticity induced by inhibitory neuron transplantation. Science 237:1145-1148. Medline

Takesian AE, Hensch TK (2013) Balancing plasticity/stability across brain development. Prog Brain Res 207:3-34. CrossRef Medline

Trachtenberg JT, Trepel C, Stryker MP (2000) Rapid extragranular plasticity in the absence of thalamocortical plasticity in the developing primary visual cortex. Science 287:2029-2032. CrossRef Medline

van Versendaal D, Levelt CN (2016) Inhibitory interneurons in visual cortical plasticity. Cell Mol Life Sci 73:3677-3691. CrossRef Medline

Vinck M, Batista-Brito R, Knoblich U, Cardin JA (2015) Arousal and locomotion make distinct contributions to cortical activity patterns and visual encoding. Neuron 86:740-754. CrossRef Medline

Zhang S, Xu M, Chang WC, Ma C, Hoang Do JP, Jeong D, Lei T, Fan JL, Dan Y (2016) Organization of long-range inputs and outputs of frontal cortex for top-down control. Nat Neurosci 19:1733-1742. CrossRef Medline 